\title{
Educação Permanente em Saúde na formação da Rede Brasileira de Escolas de Saúde Pública
}

\author{
Permanent Education in Health in the formation of the Brazilian \\ Network of Public Health Schools
}

Rosa Maria Pinheiro Souza, $\mathbf{1}^{\mathbf{2}}$, Patrícia Pol Costa $\mathbf{1 , 2}$

DOI: 10.1590/0103-11042019S110

RESUMO O presente artigo traz o relato da concepção e implementação de cursos de especialização em saúde pública em dez instituições públicas formadoras que integram a Rede Brasileira de Escolas de Saúde Pública (RedEscola). A iniciativa, inovadora pela metodologia educacional proposta, baseou-se nos princípios e diretrizes da Educação Permanente em Saúde, tendo a valorização do trabalho como eixo pedagógico, a atuação no território e o uso de metodologias ativas no processo ensino-aprendizagem.

PALAVRAS-CHAVE Educação continuada. Escolas de saúde pública. Saúde pública. Política de saúde.

\begin{abstract}
This article presents the report of the conception and implementation of specialization courses in public health in ten public educational institutions that integrate the Brazilian Network of Public Health Schools (RedEscola). This initiative, innovative due to its educational methodology, was based on the principles and guidelines of Permanent Education in Health, having the valuation of work as a pedagogical axis, the territorial action, and the use of active methodologies in the teaching-learning-process.
\end{abstract}

KEYWORDS Education, continuing. Schools, public health. Public health. Health policy. 


\section{Introdução}

A Rede Brasileira de Escola de Saúde Pública (RedEscola) é uma organização de adesão voluntária composta por 53 instituições públicas de ensino em saúde distribuídas em todo o território nacional, a qual, em 2018, completou uma década de existência. A RedEscola desenvolveu-se com o objetivo de articular e fortalecer as escolas, núcleos e centros formadores em saúde pública e em saúde coletiva em instituições de ensino superior, visando à produção do conhecimento e à qualificação dos trabalhadores atuantes no Sistema Único de Saúde (SUS).

Sua gênese deu-se no âmbito da Escola Nacional de Saúde Pública Sergio Arouca da Fundação Oswaldo Cruz (Ensp/Fiocruz) a partir do Projeto Regesus, convênio celebrado entre a Secretaria de Gestão do Trabalho e da Educação em Saúde do Ministério da Saúde e a Ensp em 2008. O Projeto permitiu a realização de uma pesquisa de caráter quantitativo e qualitativo, naquele momento, com 18 instituições formadoras em saúde pública no Brasil. Os resultados encontrados apontaram ser de suma importância um estudo de caráter prospectivo, que pudesse fornecer algumas bases de construção de uma rede formativa em saúde pública, articulada com as diretrizes gerais de formação da política de saúde, procurando também resgatar as especificidades inerentes às demandas e às ofertas locais e regionais'.

As estratégias de trabalho em rede têm sido referidas como o alicerce fundamental à execução e consolidação de ações imprescindíveis para a educação e o trabalho no SUS. Nesses dez anos, portanto, a RedEscola vem propiciando a circulação de informações, a difusão de metodologias e o compartilhamento de saberes e práticas para enfrentar desafios comuns.

Amparada por uma Secretaria Técnica Executiva baseada na Ensp, da Fiocruz, a RedEscola conta com um Grupo de Condução (GC) composto por dez representantes das instituições que a integram, distribuídos de forma equânime pelas regiões do Brasil. O GC é eleito na Plenária dos Encontros Nacionais da Rede, que acontecem anualmente. A Plenária é também a instância responsável pela aprovação do regulamento que conduz os princípios, diretrizes e valores que norteiam as ações desenvolvidas.

Os valores da RedEscola estão pautados em seis pilares: inclusão de atores, saberes e novas experiências; reconhecimento da diversidade como ponto de partida para o crescimento; solidariedade, expressa por ações solidárias que permitam o apoio mútuo entre as instituições e que contribuam para o seu fortalecimento nos territórios específicos; gestão democrática; sustentação de um espaço que fomente a aprendizagem permanente; a confiança entre os atores que se dedicam à tarefa de formar novos profissionais para atuação no campo da saúde pública/coletiva; e, finalmente, a Educação Permanente em Saúde (EPS).

O relato do processo de concepção e implementação do projeto de Formação em Saúde Pública, desenvolvido no âmbito da RedEscola, que inaugurou um novo ciclo de formação de sanitaristas no Brasil, e a inter-relação desta experiência inovadora com os marcos conceituais da EPS são o foco do presente artigo.

Redesenhar as bases de formação em saúde pública no Brasil constitui-se em um dos principais desafios das instituições formadoras nesse campo, engajadas na construção de uma formação pautada segundo as necessidades e a realidade do SUS. Trata-se de um desafio que converge com os princípios e diretrizes da EPS, política empenhada na valorização do caráter social da ação educativa nos processos de trabalho coletivo.

\section{Material e métodos}

Na elaboração deste artigo, foram utilizados documentos produzidos pela Secretaria Técnica Executiva da RedEscola, que registrou todas as etapas do projeto de Formação em Saúde Pública, desde a concepção dos cursos até sua implementação. Trata-se, desse modo, 
de pesquisa exploratória, apoiada por referenciais bibliográficos e ampla análise documental, a partir dos relatórios de atividades do projeto que inclui seminários de avaliações e reuniões e dos relatórios apresentados pelas dez instituições formadoras responsáveis pelo desenvolvimento dos cursos de especialização em Saúde Pública nas cinco regiões brasileiras, com dois estados contemplados por região.

Entre esses referenciais, destaca-se a pesquisa realizada pela RedEscola com o apoio do Conselho Nacional de Desenvolvimento Científico e Tecnológico (CNPq) e do Ministério da Saúde, no intuito de refletir sobre o papel e sobre a posição das instituições formadoras na configuração da Política Nacional de Educação Permanente em Saúde (PNEPS). Intitulada 'A Política Nacional de Educação Permanente em Saúde vivenciada nas Escolas de Saúde Pública: contribuições para reflexão a partir da prática', a pesquisa foi desenvolvida entre 2014 e 2016, contemplando inicialmente cinco instituições formadoras integrantes da Rede. Essa seleção considerou, além do critério regional, a participação ativa na discussão em EPS no âmbito da RedEscola e a atuação nos Polos de Educação Permanente ou nas Comissões de Integração Ensino-Serviço (Cies) ${ }^{2}$.

Foram realizadas cinco oficinas, uma por região do Brasil. Fizeram parte dessa pesquisa a Escola de Saúde Pública do Paraná, cuja oficina aconteceu nos dias 7 e 8 de abril de 2015; a Escola de Saúde Pública de Minas Gerais, nos dias 11 e 12 de maio de 2015; a Escola Tocantinense do SUS, em 20 e 21 de agosto de 2015 e a Escola de Saúde Pública de Goiás, nos dias 27 e 28 de agosto de 2015. Já a Escola de Saúde Pública de Pernambuco, realizou sua oficina em 9 e 10 de março de 2016.

A pesquisa estendeu-se ainda a instituições locais parceiras, envolvendo mais quatro escolas: a Escola de Saúde Pública do Município de Aparecida de Goiânia - GO, a Escola de Saúde Pública do Município de Goiânia - GO, a Escola de Saúde Pública do Município de Palmas - TO e o Centro de Pesquisas Aggeu Magalhães/Fiocruz - PE.
Com o objetivo de analisar as bases conceituais e organizacionais da PNEPS, tendo como referência as experiências das Escolas vinculadas à Rede, foram realizadas cinco oficinas envolvendo as nove instituições formadoras nomeadas acima. Esses eventos tiveram como dinâmica o diálogo entre a equipe de pesquisa e os participantes das instituições, em uma construção colaborativa de conhecimento. Concebidas a partir de uma metodologia comum, as oficinas tinham a possibilidade, entretanto, de adaptar o roteiro proposto de acordo com a relação com os pesquisadores e o contexto. Cada encontro teve duração de 12 horas, foi gravado e forneceu elementos para o processo de sistematização final.

\section{EPS e atuação em rede - algumas considerações}

A EPS considera o trabalho como seu eixo estruturante, uma vez que é nesse espaço que ocorrem as práticas a serem realizadas. Ela foi alavancada pela PNEPS, instituída pela Portaria GM/MS n ${ }^{\circ} 198$, de 13 de fevereiro de 2004, que passou a compor o fundamento da política de gestão da educação na saúde, visando à formação e ao desenvolvimento de trabalhadores para o SUS. Posteriormente, a Portaria foi revista pela Portaria GM/MS n ${ }^{\circ}$ 1.996, de 20 de setembro de 2007, que alterou seus mecanismos operacionais nos estados, mas manteve intacto seus princípios ${ }^{3}$.

A EPS, em seus pressupostos conceituais e metodológicos, é entendida como uma estratégia transformadora dos paradigmas da formação e das práticas de saúde, assim como para o desenvolvimento pessoal, social e cultural, em que o sujeito é ativo quanto ao seu processo de aprendizagem ${ }^{4}$.

Situada como estratégica para a formação dos trabalhadores do SUS, a EPS se orienta para a recomposição das práticas de saúde, buscando articular ensino, atenção, gestão e controle social em saúde, configurando o que ficou conhecido como 'quadrilátero da 
Educação Permanente em Saúde'2 . Cabe aos atores que compõem o quadrilátero (gestores, instituições de ensino, trabalhadores e controle social) a construção coletiva de estratégias para a negociação e pactuação de problemas ${ }^{5}$.

Ao abordar a EPS na formação para a saúde, considera-se que o serviço, o trabalho, a atenção, a educação, a qualidade e a cidadania têm como finalidade ou razão de ser a contribuição à satisfação das necessidades individuais e coletivas da população. Para sustentar esse enfoque, propõe-se revisar algumas categorias importantes a fim de que se construa outra concepção de serviço de saúde ${ }^{6}$.

Nessa medida, a EPS propõe que a formação dos trabalhadores do SUS tome como referência as necessidades e a realidade de saúde do território, transformando as práticas e a organização do trabalho em saúde, por meio da reflexão crítica desses profissionais quanto a seus processos cotidianos de trabalho. Para tanto, sob o ponto de vista pedagógico, preconiza que o processo favoreça a adoção de metodologias ativas do conhecimento, segundo as quais o estudante é sujeito ativo nos processos de ensino aprendizagem, centrados na problematização?.

Uma educação problematizadora estabelece uma relação dialética entre educador e educando, rompendo a lógica individual e vertical, ao compreender que ambos aprendem juntos durante o processo ${ }^{8}$. Enfatiza ainda a importância de 'pensar na prática', ou seja, a reflexão teórica se dá sobre um problema real, encontrado no cotidiano das práticas, e busca levantar hipóteses sobre suas causas a fim de intervir sobre o problema enfrentado com o objetivo de resolvê-lo9.

No contexto dos serviços de saúde, as pedagogias problematizadoras favorecem o trabalho em equipe, transformando, aprimorando e qualificando a atuação profissional. A complexidade e a diversidade de ações desenvolvidas nos serviços, bem como dos atores que compõem esse espaço, são levadas em conta, gerando conhecimentos mais adequados ao contexto, que ultrapassam o conhecimento exclusivamente técnico, a despeito da valorização conferida pela EPS à atualização científica e tecnológica. A partir da reflexão sobre a realidade, o trabalho torna-se fonte de conhecimento e invenções. Desse modo, expande-se a consciência da equipe, com a inclusão de trabalhadores e usuários, sem perder de vista os mecanismos de gestão que ali atuam.

Alguns trabalhadores da saúde podem mostrar-se resistentes, a princípio, para ouvir os relatos dos usuários, gestores e até da própria equipe com a qual trabalham. Muitos autores, porém, descrevem que, a cada reunião entre as equipes e demais atores, todos recebiam uma série de informações adicionais, que os esclareciam e diminuíam as resistências em torno da construção coletiva de soluções aos problemas apresentados ${ }^{10}$.

Ao situar a EPS como um valor, a RedEscola incorpora tais princípios aos seus próprios processos, seja em sua governança de caráter democrático e participativo, seja em sua atuação, mais notadamente no desenvolvimento de ações educativas em rede.

Túlio Franco sinaliza as redes como potencialmente capazes de construir sujeitos desejantes e aptos a transformar a realidade. Para o autor, o cotidiano das práticas de saúde se caracteriza por permanentes fluxos operativos, políticos, comunicacionais e simbólicos, que, consubstanciados em rede, atribuem aos trabalhadores a ideia de pertencimento entre eles e entre os trabalhadores com as equipes de saúde, assim como a uma rede maior que opera, por meio de fluxos conectivos com demais equipes e com os usuários"1.

A EPS, portanto, ao romper a verticalização dos saberes e das práticas, proporciona a democratização dos espaços de saúde, já que pressupõe a construção coletiva de estratégias de atuação e enfrentamento dos problemas específicos de um determinado local, em um determinado território.

Assim, a atuação estratégica da RedEscola, seu agir democrático e participativo, a transformam em um dispositivo ainda mais potente 
para a concepção e implementação de ações formativas que valorizem os princípios e diretrizes políticos, operacionais e pedagógicos consubstanciados pela EPS.

Nesse sentido, a EPS é um processo profundamente democrático, pois implica começar a aprender a perguntar, e não a estabelecer respostas prontas. Para que isso ocorra, a EPS demanda organizações mais democráticas e a construção de espaços que possibilitem a reflexão. Nessa perspectiva, busca romper com a verticalização do sistema de saúde, criando espaços de enfrentamentos de problemas na realidade do trabalho dos profissionais ${ }^{\mathbf{1 2}}$.

As atividades das instituições formadoras que a integram têm seus processos formativos pautados pelas políticas de saúde normalmente demandadas a partir do Ministério da Saúde, mas, pela natureza de sua missão, que é formar trabalhadores para o SUS, elas contam com a RedEscola como uma instância favorável à construção de consensos em torno da EPS.

Tal construção permite que as ações desenvolvidas em seu âmbito se encontrem mais alinhadas às realidades e necessidades locais, possibilitando maior efetividade dos resultados esperados, mais especificamente, a transformação do ensinar e aprender, assim como das práticas de saúde. Agir regionalmente é uma estratégia que dialoga com a EPS, com vistas ao desenvolvimento ao desenvolvimento de iniciativas inovadoras capazes de enfrentar os desafios colocados para a implementação do SUS com qualidade ${ }^{\mathbf{1 3}}$.

\section{Nova formação em Saúde Pública - uma experiência em Rede}

A formação de trabalhadores para o SUS pode ser considerada com um dos pilares de sustentação do SUS. A formação em saúde pública no âmbito da RedEscola começou a ganhar contornos mais definidos quando a Secretaria Executiva realizou um levantamento nas instituições que a compõem acerca da formação de sanitaristas. O levantamento demonstrou que a maioria dos cursos de especialização oferecidos atendia às demandas imediatas da gestão, que não incluíam a formação de sanitaristas, sendo esta residual no território brasileiro, o que, por consequência, gera uma lacuna importante na oferta de cursos para sanitaristas no País.

Para a RedEscola, era preciso desenvolver uma ação capaz de redesenhar as bases de formação em saúde pública, considerando as novas agendas do SUS e a perspectiva do território como espaço de intervenção sanitária e social, além de prover as Escolas de condições para o desenvolvimento de um novo ciclo de formação de sanitaristas que fortalecesse, além das próprias instituições formadoras, as políticas públicas de educação na saúde na perspectiva da EPS.

Foi então elaborado o projeto de nova formação de sanitaristas aqui focalizado, coordenado pela RedEscola por meio de um termo de cooperação entre a Secretaria de Gestão do Trabalho e da Educação na Saúde (SGTES/ MS) e a Ensp/Fiocruz. Depois de aprovado pela SGTES/MS, o projeto previa a oferta de curso de especialização para 30 alunos em 10 instituições integrantes da Rede, em 2 turmas, formando um total de 600 novos sanitaristas.

Seguindo os preceitos da gestão democrática, horizontal e participativa, a RedEscola deu início ao processo de concepção e implementação da formação por meio da realização de diversas oficinas com o GC, professores e pesquisadores da Ensp/Fiocruz, além da Secretaria Executiva da Rede e dirigentes e docentes das Escolas envolvidas na ação.

O ponto fundamental era que os estudantes tivessem o protagonismo de seus processos educativos a partir de seus saberes e de sua prática cotidiana no seu território de atuação. Para tanto, deveriam conhecer a história, a política e a cultura desses territórios. As unidades de aprendizagem teriam, portanto, de mobilizar esses saberes e as diferentes práticas e realidades locais pertinentes a cada instituição formadora. Em resumo, o grande diferencial 
do projeto é que cada Escola construiria o seu curso, conforme sua realidade, necessidades e características do seu território.

A construção coletiva de uma ação educativa, como no caso da formação em saúde pública da RedEscola, pauta-se também por um agir comunicativo que se estende até o mundo do trabalho. Para Silva e Peduzzi ${ }^{\mathbf{1 4}}$, essa representação pode ser denominada comunicativa, ou emancipatória, a partir do momento que agrega o Quadrilátero da EPS, podendo, ainda, avançar no contexto da interprofissionalidade, contribuindo para amplificar vozes e pensamentos, contribuindo para a reflexão mais efetiva sobre as práticas e sobre o cuidado em saúde.

Inicialmente, foram traçadas as diretrizes prioritárias para o curso, o cronograma de atividades e os critérios para a identificação das Escolas que participariam do projeto. Entre esses critérios, estavam a distribuição regional equitativa das Escolas, o interesse demonstrado pela instituição e a certificação, por elas, dos cursos lato sensu. Enfim, foram elencadas as seguintes Escolas: Escola de Saúde Pública de Pernambuco, Escola de Saúde Pública do Ceará, Escola de Saúde Pública da Bahia, Escola Tocantinense do SUS, Universidade Federal do Acre, Escola de Saúde Pública do Paraná, Escola de Saúde Pública do Rio Grande do Sul, Escola de Saúde Pública de Minas Gerais, Escola de Saúde Pública de Goiás e Escola de Saúde Pública de Mato Grosso.

Para debater e traçar o desenho pedagógico dos cursos, a RedEscola organizou três Oficinas de Concepção dos Cursos de Especialização em Saúde Pública. A primeira grande oficina, realizada em agosto de 2015, aprofundou a reflexão acerca do projeto político pedagógico a partir de três perguntas norteadoras:

1. O que esperamos de um sanitarista no SUS hoje?

2. Que temas e questões são importantes para a formação desse sanitarista?

3. Que estratégias metodológicas e processos pedagógicos são necessários para a construção dessa formação? ${ }^{15(32) .}$
Uma segunda oficina de trabalho, realizada em novembro do mesmo ano, estabeleceu os princípios e pressupostos, objetivos e perfil dos egressos. Neste ensaio, será feito um recorte, com destaque para os princípios e pressupostos, a seguir apresentados.

Princípios e Pressupostos da formação de novos sanitaristas:

1 - A defesa da saúde como um bem público.

2 - O compromisso com a formação para o Sistema Único de Saúde.

3 - A sustentação de uma formação pautada pelos princípios e diretrizes do SUS.

4 - O compromisso com os direitos humanos e uma formação ético-política.

5 - O compromisso com a responsabilidade socioambiental, o cuidado com o ambiente e a humanidade.

6 - A valorização da dimensão do cuidado.

7 - O trabalho como princípio educativo.

8 - O estabelecimento de uma nova práxis que valorize o compartilhamento de conhecimentos e saberes.

9 - A adoção de uma perspectiva pedagógica dialógica e transformadora.

10 - A valorização do trabalho em equipe multiprofissional e interdisciplinar.

11 - A valorização do território como espaço de produção de conhecimento.

12 - A participação social como princípio formativo.

13 - A investigação como busca ativa do conhecimento.

14 - A comunicação como prática educativa.

15 - A avaliação como parte da própria ação educativa e como ferramenta de apoio para a qualificação da prática15(32).

Nota-se, que, dos 15 princípios consensuados nas Oficinas de trabalho, seis estão diretamente relacionados com os princípios e diretrizes da educação permanente: o trabalho como princípio educativo, o estabelecimento de uma nova práxis que valorize o compartilhamento de conhecimentos e saberes, a 
adoção de uma perspectiva pedagógica dialógica e transformadora, a valorização do trabalho em equipe multiprofissional e interdisciplinar, a valorização do território como espaço de produção de conhecimento e a participação social como princípio formativo.

Uma última Oficina de trabalho, ainda antes da implementação do projeto nas Escolas, tratou de compartilhar as experiências alcançadas até aquele momento, quando já era possível identificar a grande movimentação causada pela lógica proposta.

A imagem a seguir apresenta de forma sistemática o processo de construção coletiva para o desenvolvimento dos cursos nas instituições formadoras.

Figura 1. Esquema das Oficinas para a concepção do Curso de Especialização em Saúde Pública

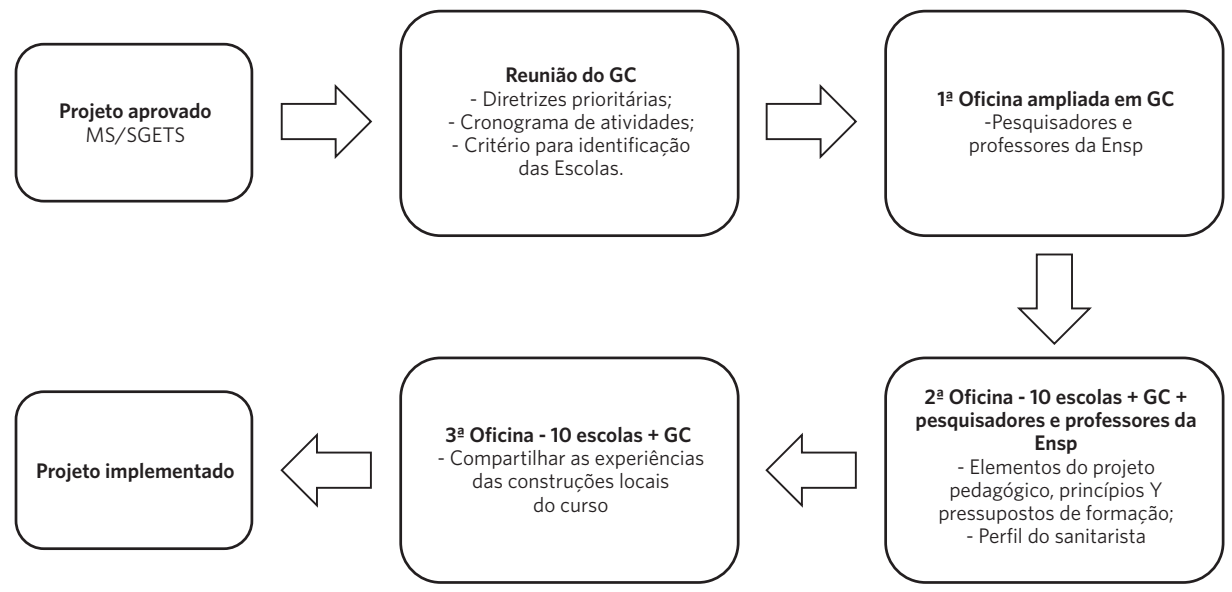

Fonte: Secretaria Técnica e Executiva RedEscola16

Destaca-se ainda que, durante todo o processo, a RedEscola propiciou momentos de trocas de experiência entre as instituições formadoras, nos quais alguns resultados podiam ser observados, sobretudo, quanto às metodologias ativas utilizadas para dar conta da proposta pedagógica da formação.

Mesmo que os números alcançados pela formação em saúde pública sejam contundentes, eles não conseguem traduzir na prática o movimento alcançado no interior de cada instituição. A pujança dessa iniciativa, a quantidade de atores, trabalhadores e instituições envolvidas, além da meta alcançada, podem ser visualizadas na figura a seguir. 


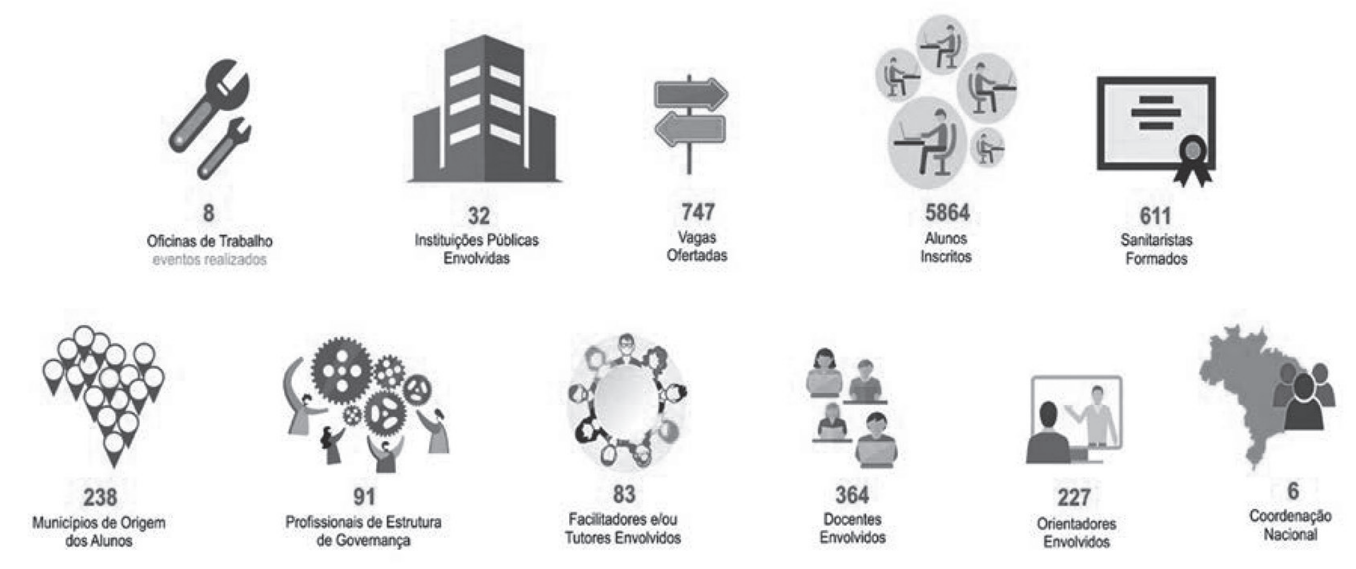

Fonte: Elaboração própria.

Ilustração: Adriana Carvalho.

É importante destacar que todas as instituições envolvidas realizaram reuniões, seminários ou oficinas com seus respectivos corpos docentes a fim de discutirem as estratégias metodológicas, condução do Trabalho de Conclusão de Curso (TCC), dificuldades e alternativas. Tal constatação demonstra o potencial da formação na busca de operar pedagogicamente de acordo com a EPS.

Pode-se afirmar, a partir dos resultados observados, e também em acordo com o que apontou a pesquisa 'A Política Nacional de Educação Permanente em Saúde vivenciada nas Escolas de Saúde Pública: contribuições para reflexão a partir da prática', que os princípios e valores da EPS foram apropriados pelas instituições formadoras, fazendo-se presentes não apenas nos processos formativos como também na própria gestão e atuação política. Tornou-se evidente o importante papel que as Escolas de Saúde Pública têm desempenhado como indutoras da execução da política de EPS ${ }^{16}$.

Nas duas Oficinas de avaliação do projeto de formação, realizadas em março e julho de 2018, quando as Escolas puderam dialogar mais profundamente sobre os impactos do uso de metodologias ativas em suas instituições, concluiu-se que a EPS foi uma estratégia potente para a formação crítico-reflexiva. $\mathrm{O}$ método do Arco, de Charles Maguerez, ou da problematização, foi uma das ferramentas pedagógicas utilizada em boa parte das instituições envolvidas no projeto.

Os relatos também comprovaram que o modo de trabalhar em rede foi determinante para o desenvolvimento dos cursos, já que, desde a sua concepção, as instituições participantes aglutinaram-se em torno dos princípios e diretrizes coletivamente construídos, apoiando-se mutuamente por meio do compartilhamento de saberes e experiências.

Em que pesem, contudo, os avanços alcançados, as instituições refletiram que ainda há muito o que avançar em torno das metodologias ativas de aprendizagem e propuseram a formação de um Grupo de Trabalho que buscasse caminhos para o desenvolvimento desse conhecimento em suas instituições por meio da formação docente.

A identificação dessa lacuna inspirou a inclusão da discussão sobre as Metodologias de Aprendizagem no Encontro Nacional da RedEscola e gerou dois capítulos no livro intitulado RedEscola e a nova formação em 
saúde pública: 'Metodologias ativas': entre movimentos, possibilidades e propostas, de autoria de Marise Ramos: e Metodologias ativas na formação de profissionais da Saúde: uma possibilidade para as necessidades da população, de Laís Alves de Souza.

As instituições formadoras envolvidas construíram um conjunto de dinâmicas visando à formação docente, no sentido de reforçar a EPS como uma estratégia importante para desenvolver uma aprendizagem significativa e, sobretudo, que fizesse sentido para os novos sanitaristas, diante dos novos e velhos desafios a serem enfrentados.

As escolas têm sido inegavelmente um espaço vivo e privilegiado para a discussão sobre a PNEPS e para o exercício em ato de seus aportes como política de educação na saúde, constituindo-se em verdadeiros laboratórios de inovação envolvendo a gestão, a educação, o trabalho e o controle social.

Do caminho trilhado até agora, viu-se reforçada a importância das articulações e trocas entre os integrantes da Rede, que contribuiu tanto para a apropriação de novos conhecimentos quanto para a proposição de inovações no campo de formação em saúde pública dentro dos princípios da EPS, com vistas ao fortalecimento do SUS.

Por fim, destaca-se a repercussão que essa experiência trouxe para as instituições formadoras envolvidas nesse projeto, na medida em que proporcionou a incorporação de novas expertises, com introdução de tecnologias pedagógicas e inovações metodológicas.

Uma segunda publicação, lançada em 2019, avança na temática ao introduzir um capítulo sobre a Educação Interprofissional (EIP) e apresenta também as experiências, o aprendizado e as lições compartilhadas ${ }^{16}$.

Ao agregar na formação uma abordagem mais comprometida com a realidade social dos territórios, fez emergir a necessidade de assumir a EIP como uma estratégia potente para o desenvolvimento de práticas colaborativas, visando à melhoria da atenção à saúde. Tais ganhos estimularam as instituições que desenvolveram a formação de sanitarista a introduzir os conhecimentos e saberes gerados na concepção e desenvolvimento de outros processos formativos.

\section{Considerações finais}

As iniciativas da RedEscola apresentadas neste ensaio permitem reafirmar que houve um incontestável movimento entre as 10 instituições formadoras envolvidas na concepção e implementação de cursos de saúde pública na valorização da EPS, como um dispositivo importante na formação para o SUS.

O fato de cada instituição formadora ter elaborado o projeto pedagógico do curso a partir dos pressupostos e princípios da formação de sanitaristas, construídos coletivamente, dos quais seis estão diretamente coadunados com os princípios e diretrizes da educação permanente, denota incontestavelmente uma apropriação das bases e dos fundamentos da EPS, e corrobora os achados da pesquisa denominada Política Nacional de Educação Permanente em Saúde - Experiência Viva na Rede Brasileira de Escolas de Saúde Pública.

A valorização do trabalho como eixo pedagógico associada à introdução de metodologias ativas no processo ensino-aprendizagem, à reflexão sobre a realidade expressa nos projetos de intervenção, afinados com as demandas e necessidades do território que se constitui como locus privilegiado de transformação, ensejaram um conjunto de experiências ricas e inovadoras, apresentadas neste estudo.

Há que se considerar também os significativos esforços engendrados pela SGETS do Ministério da Saúde, com destaque para o Programa para o fortalecimento das práticas de Educação Permanente em Saúde (Proeps - SUS) o que certamente contribuiu para fortalecer as ações de EPS no País ${ }^{17}$.

Apesar dos resultados alcançados, torna-se necessário avançar na formação docente alinhada aos princípios e diretrizes da EPS; e 
ainda na promoção da EIP na EPS como uma importante estratégia para o desenvolvimento de práticas colaborativas no SUS.

\section{Colaboradores}

Souza RMP (0000-0003-3204-0835)* e Costa PP (0000-0003-3527-6974)*, contribuíram da mesma forma para a concepção, planejamento, elaboração e revisão crítica do artigo, bem como aprovaram a versão final do manuscrito.

\section{Agradecimentos}

Agradecemos às equipes de todas as instituições formadoras que participaram das ações desenvolvidas no âmbito da RedEscola e que nos inspiraram na escrita desse artigo.

\section{Referências}

1. Nunes TC, coordenadora. Projeto REGESUS 538. Relatório Final. Pesquisa Nacional das Escolas de Saúde Pública. Inovações na Educação em Saúde Pública com diálogo e parceria. Rio de Janeiro: Ministério da Saúde, Fiocruz; 2008.

2. Cardoso MLM, Pol P, Xavier C, et al. A Política Nacional de Educação Permanente em Saúde nas Escolas de Saúde Pública: reflexões a partir da prática. Ciênc. Saúde Colet. [internet] 2017 [acessos em 2018 out 16]; 22(5):1489-1500. Disponível em http://dx.doi. org/10.1590/1413-81232017225.33222016.

3. Brasil. Ministério da Saúde. Portaria $n^{\circ} 198$, de fevereiro de 2004. Implementa a Política Nacional de Educação Permanente em Saúde. Ministério da Saúde como estratégia do Sistema Único de Saúde (SUS) para a formação e o desenvolvimento de trabalhadores para o setor. Diário Oficial da União. Brasília, DF, 14 Fev 2004.

4. França TM, Belisario KR, Garcia AS, et al. Política de
Educação Permanente em Saúde no Brasil: a contribuição das Comissões Permanentes de Integração Ensino-Serviço. Ciênc. Saúde Colet. (2017); 22(6):1817-1828.

5. Ceccim RB, Feuerwerker LCM. O quadrilátero da formação para a área da saúde: ensino, gestão, atenção e controle social. Physis. 2004; 14(1):41- 65.

6. Quintana PB, Roschke MAC, Ribeiro ECO. Educación Permanente, processo de trabajo y calidad de servicio en salud. In: Haddad J, Roschke MALC, Davini MC, organizadores. Educación Permanente de Personal de Salud Washington: Organizacion Panamericana de la Salud; 1994. Série Desarrollo de Recursos Humanos $\mathrm{n}^{\circ} 100$. p. 34-60.

7. Brasil. Ministério da Saúde. Política de Educação Permanente e Desenvolvimento para o SUS Caminhos para Educação Permanente em Saúde, Brasília, DF: Ministério da Saúde, 2004.
${ }^{*}$ Orcid (Open Researcher and Contributor ID). 
8. Freire P. Pedagogia do oprimido. 17. ed. Rio de Janeiro: Paz e Terra; 1987.

9. Davini MC. Educación Permanente de Personal de Salud. Organizacion Panamericana de la Salud; 1994. Série Desarrollo de Recursos Humanos n ${ }^{\circ} 100$ Washington, DC: OPS; 1994. p. 33-61.

10. Slomp JH, Feuerwerker LCM, Merhy EE. Histórias de vida, homeopatia e educação permanente: construindo o cuidado compartilhado. Ciênc. Saúde Colet. 2015; 20(6):1795-1803.

11. Franco TB. As Redes na Micropolítica do Processo de Trabalho em Saúde. In: Pinheiro R, Matos RA. “Gestão Em Redes”. Rio de Janeiro: LAPPIS-IMS, UERJ, ABRASCO; 2006.

12. Rovere MR. Gestion de La Educación permanente: uma relectura desde uma perspectiva estratégica. Educ. Med. Salud. 1993; 27(4): p. 63-106.

13. Brasil. Ministério da Saúde, Secretaria de Gestão do Trabalho e da Educação na Saúde. Política Nacional de Educação Permanente em Saúde: o que se tem produzido para o seu fortalecimento? 1. ed. rev. Brasília, DF: Ministério da Saúde; 2018.
14. Silva JAM, Peduzzi M. Educação no trabalho na atenção primária à saúde: interfaces entre a educação permanente em saúde e o agir comunicativo. Saúde Soc. 2011; 20(4):1018-1032.

15. Souza RMP, Pol PP, organizadoras. Redescola e a nova formação em saúde pública. Rio de Janeiro: Fiocruz; 2017.

16. Souza RMP, Costa PP, organizadoras. Nova Formação em Saúde Pública: aprendizado coletivo e lições compartilhadas na RedEscola. Rio de Janeiro, RJ: Fiocruz; 2019. v. 2.

17. Brasil. Ministério da Saúde. Manual Técnico 2018: Programa para o fortalecimento das Práticas de Educação Permanente em Saúde. [internet]. Brasília, DF: Ministério da Saúde; 2018. [acesso em 2018 mar 12]. Disponível em: http://portalarquivos2.saude.gov. br/images/pdf/2018/dezembro/13/Manual-TecnicoPRO-EPS-SUS-MINUTA17-FINAL.pdf.

Recebido em 30/10/2018

Aprovado em 18/04/2019

Conflito de interesses: inexistente

Suporte financeiro: não houve 